\title{
Distress and drinking: Cross-cultural connections and contexts*
}

\author{
Richard W. Wilsnack, Arlinda F. Kristjanson, Sharon C. Wilsnack and Perry W. Benson \\ Department of Clinical Neuroscience, University of North Dakota School of Medicine and Health Sciences
}

\section{ABSTRACT}

Aims: Research on how distress is related to drinking has paid relatively little attention to gender and to cultural differences. This study examines how distress is associated with men's and women's drinking cross-culturally.

Design: Cross-sectional survey.

Setting/Participants: Surveys of 30,728 women and 24,204 men in 22 countries of the GENACIS project (Gender, Alcohol and Culture: An International Study) provided data on how women's and men's mental, interpersonal and work-situational distress are related to their drinking patterns.

Measurements: Analyses examined correlations within surveys, and used hierarchical linear modeling (HLM) to take into account economic development, abstinence rates and distress levels in the populations surveyed.

Findings: We found few associations of drinking patterns with reported stressful work situations. Mental and interpersonal distress had more frequent but geographically scattered associations with men's and women's drinking, particularly with quantities consumed. HLM analyses confirmed cross-culturally that drinking tended to increase with psychological and interpersonal distress, but the societal-level variables had few effects.

Conclusions: Distress measures in GENACIS surveys were positively though not powerfully associated with both women's and men's drinking cross-culturally, associations not attributable to societal-level characteristics. The findings indicate a need for better cross-cultural information about the processes by which distress may lead to heavier drinking.

For over 50 years, hundreds of scholars have tried to learn how distress is connected to drinking. From all their efforts, one conclusion is certain: sometimes emotional and physical distress are associated with heavier drinking and increased risks of alcohol problems and alcohol disorders. However, after much time and effort, it is still not clear how or when or where or why distress and drinking are connected. Here we briefly review some of the more common findings from recent research, and then offer more information about where distress and drinking occur together and how gender may affect the connections.

A basic hypothesis about stress and alcohol is that for people who drink, the effects of alcohol seem to help them deal with unpleasant feelings resulting from stressful experiences. Evidence consistent with this hypothesis has been found in a wide variety of circumstances, in those who suffer from social anxiety disorder or symptoms (Carrigan

Correspondence: Richard W. Wilsnack, Department of Clinical Neuroscience, University of North Dakota School of Medicine and Health Sciences, Grand Forks, North Dakota 58202-9037, U.S.A.

E-mail: richard.wilsnack@med.und.edu

Financial support: See Acknowledgments

Keywords: alcohol, stress, cross-cultural, gender

* An earlier version of this paper was presented at the KBS Thematic Meeting on Alcohol Epidemiology and Policy, Kampala, Uganda,

November I7, 2010 
\& Randall, 2003; Morris, Stewart, \& Ham, 2005; Schneier et al., 20Io; Zimmermann et al., 2003), posttraumatic stress disorder or symptoms (Blume, Resor, Villanueva, \& Braddy, 2009; Jacobson et al., 2008; McDevitt-Murphy et al., 2010), physical pain (Lawton \& Simpson, 2009; Moos, Brennan, Schutte, \& Moos, 20I0; Riley \& King, 2009), cumulative experience with stressful life events (Aseltine \& Gore, 2000; Dawson, Grant, \& Ruan, 2005; Lloyd $\&$ Turner, 2008), after-effects of military combat (Jacobsen et al., 2008; Šakušić et al., 2009; Wilk et al., 20IO), after-effects of disasters and terrorism (Boscarino, Adams, \& Galea, 2006; Grieger, Fullerton, Ursano, \& Reeves, 2003; Hasin, Keyes, Hatzenbuehler, Aharonovich, \& Alderson, 2007), after-effects of childhood trauma (Sarin \& NolenHoeksema, 20ıо; Wilsnack, Wilsnack, Kristjanson, Vogeltanz-Holm, \& Harris, 2004; Wu et al., 2010), after-effects of assault and criminal victimization (Kaysen et al., 2007; Ullman, Filipas, Townsend, \& Starzynski, 2005; Vaughn et al., 2010) and chronic negative emotions arising for other reasons (Costanzo et al., 2007; Dorfman, Trokel, Lincoln, \& Mehta, 20Iо; Witkiewitz \& Villarroel, 2009). Links between chronic stress and chronic drinking patterns are found more consistently than links between acute but time-limited stress and immediate drinking responses (Armeli, Todd, \& Mohr, 2005; Helzer, Badger, Searles, Rose, \& Mongeon, 2006; Skaff, Finney, \& Moos, I999; but see also Grzywacz \& Almeida, 2008; Liu, Wang, Zhan, \& Shi, 2009; Park, Armeli, \& Tennen, 2004). Stressful experiences can also be a risk factor for relapse in people recovering from alcohol dependence (Breese et al., 2005; Kushner, Abrams, \& Borchardt, 2000; Uhart \& Wand, 2008).

What is unclear, however, is how alcohol makes distressed people feel better; that is, to what extent alcohol reduces or deadens bad feelings, to what extent alcohol consumption provides temporary good feelings (such as in social drinking situations) as a time out from chronic distress, and to what extent the effects of alcohol reduce people's attention to their problems. There are also no simple conclusions about the extent to which heavy or problem drinking creates stressful experiences in addition to being a response to such experiences.

What makes the study of stress and drinking a messy task is that some studies produce contrary findings, in which stress is either unrelated to drinking or is associated with drinking less. Several studies have found no increase in drinking related to stressful life events (Droomers, Schrijvers, Stronks, Van De Mheen, \& Mackenbach, I999; Robertson, Xu, \& Stripling, 20Iо; Welte \& Mirand, I995), social anxiety (Eggleson, Woolaway-Bickel, \& Schmidt, 2004; Ham \& Hope, 2006; Tran, Haaga, $\&$ Chambless, I997) and posttraumatic stress disorder (Boscarino et al., 2006; Breslau, Davis, \& Schultz, 2003; Najdowski \& Ullman, 2009), and there are also studies reporting no drinking increase in people who have suffered pain (Yokoyama et al., 2009), sexual victimization (Testa, Livingston, \& Hoffman, 2007) and effects of military combat (Fritch, Mishkind, Reger, \& Gahm, 20I0). Workrelated stress has a particularly uncertain relationship with drinking; sometimes distressed employees drink more (Ahola et al., 2006; Bobak et al., 2005; Richman, Shinsako, Rospenda, Flaherty, \& Freels, 2002) and sometimes they do not (Hodgins, Williams, \& Munro, 2009; Kouvonen et al., 2005; $\mathrm{Ng} \&$ Jeffery, 2003). Other studies suggest that stress-induced drinking may be less common in certain age groups (such as older individuals who drink) (Graham \& Schmidt, I999; Pohorecky, I99I; Welte \& Mirand, I995) or in certain special roles (such as reduced drinking among socially anxious college students) (Ham, 2009; Ham \& Hope, 2006). It is also likely that some specific types of stress will tend to reduce rather than increase drinking, such as stress resulting from physical health problems (Brennan, Schutte, \& Moos, I999; Krause $\&$ Crewe, I990; Perreira \& Sloan, 200I).

Research has also repeatedly found stress effects on drinking that are different for men than for women. Some studies have found that women are more likely than men to begin drinking heavily or in problematic ways as an effect of social anxiety (Buckner \& Turner, 2009), trauma (Olff, Langeland, Draijer, \& Gersons, 2007) and sexual harassment (Gradus, Street, Kelly, \& Stafford, 2008). Other studies have found that men have greater tendencies than women toward heavy and problematic drinking in response to stressful life events (Dawson, Grant, \& Ruan, 2005), work stress (Bray, Fairbank, \& Marsden, I999) and unemployment (van Praag, Bracke, Christiaens, Levecque, \& Pattyn, 2009), and as a method of tension relief (Grotmol et al., 20I0). However, such gender differences are not consistently analyzed and, across the studies that do analyze gender differences, are not consistently reported.

Increasingly, studies find that connections between stressful experiences and increased alcohol 
consumption or alcohol problems depend on, or are strengthened by, mental processes or conditions. Drinking in response to distress may increase if the person expects alcohol to produce better feelings (Armeli, Carney, Tennen, Affleck, \& O’Neil, 2000; Booth \& Hasking, 2009; Ullman et al., 2005). Such drinking may also depend on whether the person thinks that the best strategy for dealing with certain stressors is to avoid or cancel out their effects, rather than to try to prevent or remove the causes of distress (which may not always be possible) (Cooper, Russell, Skinner, Frone, \& Mudar, I992; Hasking \& Oei, 2008; Richman, Rospenda, Flaherty, \& Freels, 200I). The mental strategy that most consistently connects stress to drinking is selfconscious, deliberate drinking to cope with distress. Drinking to cope is associated with more hazardous drinking and the development of alcohol use disorders (Hasking \& Oei, 2008; Gaher, Simons, Jacobs, Meyer, \& Johnson-Jiminez, 2006; Holahan, Moos, Holahan, Cronkite, \& Randall, 200I), in part because repeated heavy drinking and its effects in the brain may themselves become sources of distress, trapping the person in a vicious circle of distressdriven alcohol dependence (Koob \& Kreek, 2007; Uhart \& Wand, 2008). Recent findings suggest that people who are hypersensitive to stressors because of variations or changes in the chemistry of the brain may be particularly at risk of becoming "distressed drinkers" (Blomeyer et al., 2008; Enoch, 20II). Furthermore, research now suggests that in individuals who begin drinking very young (say, before age I4), alcohol intoxication can modify brain chemistry to make them more stress-sensitive and therefore more attracted to the effects of alcohol later on (Buchmann et al., 20ıо; Dawson, Grant, \& $\mathrm{Li}, 2007)$.

In all of this research, certain aspects of alcohol consumption have been neglected. In the literature on distressed drinking, little is said about how drinking environments encourage or discourage people from drowning their sorrows in alcohol. In particular, although there are some studies from individual sites outside North America and Western Europe (Burazeri \& Kark, 2010; Hagihara, Tarumi, \& Nobutomo, 2003; Ritter et al., 20II), there has been no systematic comparison of how stress is related to drinking in different societies around the world. Thus we do not know whether distressed drinking is a phenomenon more common to North America and Europe than to other parts of the world. Furthermore, there has been no research at all that systematically compares how, in multiple different societies, men and women drink when distressed.

We hope here to make a very modest first effort to begin to correct those omissions. Our analyses of multinational data were guided by three general hypotheses:

I. In all societies surveyed, those who scored higher on measures of distress would tend to drink more.

2. People would be more likely to use alcohol to cope with distress in places where alcohol use by their gender was widespread and commonplace.

3. People would be more likely to use alcohol to cope with distress where a higher gross domestic product meant that more people had money that they could afford to spend on alcohol.

\section{Method}

Our findings are drawn from the GENACIS project (Gender, Alcohol and Culture: An International Study), a multinational research program designed to reveal how gender is related to drinking behavior and its consequences around the world. GENACIS now includes 45 general population surveys of men and women from 38 countries in all continents except Antarctica. The GENACIS surveys were not designed specifically to evaluate how distress is related to drinking. However, 22 of the 45 GENACIS surveys, in 22 different countries on all continents, contained questions about stressful experiences or states of mind, which are the basis for this report. Locations and characteristics of these 22 surveys are summarized in Table I. Further details about GENACIS and its surveys are provided elsewhere (Taylor, Wilsnack, \& Rehm, 2008; Wilsnack, Wilsnack, Kristjanson, Vogeltanz-Holm, \& Gmel, 2009). 
Table 1

GENACIS survey characteristics

\begin{tabular}{|c|c|c|c|c|c|c|}
\hline Country & $\begin{array}{c}\text { Survey } \\
\text { year }\end{array}$ & $\begin{array}{l}\text { Age } \\
\text { range }\end{array}$ & $\begin{array}{c}\text { Women } \\
(\mathrm{N})\end{array}$ & $\begin{array}{c}\text { Men } \\
(\mathrm{N})\end{array}$ & $\begin{array}{c}\text { Sampling } \\
\text { frame }\end{array}$ & $\begin{array}{l}\text { Survey } \\
\text { mode }\end{array}$ \\
\hline Argentina & 2003 & $18-65$ & 598 & 402 & regional & face-to-face \\
\hline Australia & 2007 & $18+$ & 1,434 & 1,000 & regional & telephone \\
\hline Belize & 2005 & $18+$ & 2,070 & 1,903 & national & face-to-face \\
\hline Brazil & $2001 / 2002$ & $18+/ 17+$ & $331 / 365$ & $194 / 368$ & regional & face-to-face \\
\hline Canada & 2004 & $18-76$ & 7,872 & 5,940 & national & telephone \\
\hline Costa Rica & 2003 & $18+$ & 857 & 416 & regional & face-to-face \\
\hline Czech Republic & 2002 & $18-64$ & 1,282 & 1,244 & national & face-to-face \\
\hline Great Britain & 2000 & $18+$ & 1,038 & 963 & national & face-to-face \\
\hline India & 2003 & $16+$ & 1,250 & 1,347 & regional & face-to-face \\
\hline Isle of Man & 2005 & $18+$ & 547 & 453 & national & telephone/ face-to-face \\
\hline Japan & 2001 & $20-70$ & 1,138 & 1,116 & national & self-administered \\
\hline Kazakhstan & 2002 & $18+$ & 631 & 539 & regional & face-to-face \\
\hline New Zealand & 2007 & $18-70$ & 1,055 & 820 & national & postal \\
\hline Nicaragua & 2005 & $15+$ & 1,416 & 614 & regional & face-to-face \\
\hline Nigeria & 2003 & $18+$ & 956 & 1,114 & regional & face-to-face \\
\hline Peru & 2005 & $18-65$ & 1,015 & 516 & regional & face-to-face \\
\hline Spain & 2002 & $18+$ & 956 & 894 & regional & face-to-face \\
\hline Sri Lanka & 2002 & $18+$ & 593 & 608 & regional & face-to-face \\
\hline Sweden & 2002 & $17+$ & 2,816 & 2,656 & national & telephone \\
\hline Uganda & 2003 & $18+$ & 758 & 721 & regional & face-to-face \\
\hline Uruguay & 2004 & $18-65$ & 624 & 376 & national & face-to-face \\
\hline U.S.A. & 2001 & $21+$ & 1,126 & - & national & face-to-face \\
\hline
\end{tabular}

Six questions asked in nearly all of the 22 GENACIS surveys obtained information about distress, using numerical scales for responses. One question asked all employed individuals "How stressful is your work situation?" Two questions asked everyone, "How often during the last I2 months have you felt lonely?" and "In general, how has your emotional or mental health been in the last I2 months?" Because responses to these two questions were correlated in most surveys (poorer mental health was linked to more frequent loneliness), we combined them into a measure indicating general psychological distress. Finally, three questions asked all individuals living with a partner (married or cohabiting) about possible indicators of distress in their relationships: "How happy are you with your relationship?" "How easy is it generally for you to talk about your feelings or problems with your spouse or partner?" and "How often do you and your spouse or partner quarrel?" Responses to these three questions were correlated in most surveys, with frequent quarreling, difficulty talking about feelings or problems with one's partner, and unhappiness with the relationship tending to go together, so we combined these items into a measure indicating partnership distress. Cronbach's alphas for the two-item measure of psychological distress varied from .20 to .58 across I8 surveys, with a mean alpha of .4I, but in one survey (Nigeria) the two items correlated -.I3. Cronbach's alphas for the three-item measure of relationship distress varied from .43 to .83 across 22 surveys, with a mean alpha of .63. However, one should keep in mind that alpha values are affected by scale length, and therefore may be relatively low for scales of only two or three items (Niemi, Carmines, \& McIver, I986). 
We were able to analyze how the three measures of distress were related to four measures of alcohol consumption in the past 12 months:

- typical frequency of drinking in the past I2 months

- typical quantity consumed on a drinking day in the past I2 months (in grams of ethanol)

- volume of alcohol consumed in the past I2 months (in grams of ethanol)

- heavy episodic drinking (typically measured as 5 or more drinks in a day, and recorded as having occurred ever or never in the past I2 months).

Additional information about these measures of alcohol consumption is provided in Wilsnack et al. (2009).

Our analyses looked for differences among the societies surveyed in two ways. First, for each survey location, we examined how the measures of distress were associated with the drinking measures among men and women separately, to learn whether drinking patterns were consistently associated with distress, as hypothesized above. Because surveys varied in whether they included very young or very old subjects, we limited the age range to I8 to 65 years. We also limited the analyses to people who reported drinking more than once a month, i.e., people who drank often enough that they might show any effects of distress on how much they drank. Second, we used hierarchical linear modeling (HLM) to learn whether certain characteristics in the surveyed populations may have affected how much people drank in response to distress. The HLM analyses included measures of per capita gross domestic product (GDP) (as an indicator of national economic conditions); the percentages of men and women surveyed who abstained from drinking alcohol; mean levels of types of distress reported by men and women in the surveys; and possible interaction effects on drinking from individual stress levels combined with GDP and genderspecific prevalence of abstinence from alcohol.

\section{Results}

The single question about a stressful work situation had very few statistically significant correlations with measures of alcohol consumption, so these correlations are not presented as a table. At least 4 of the 22 countries would need to show significant correlations $(p<0.05)$ for that level of recurrence to be greater than might happen by chance $(\mathrm{p}<0.05)$. In 8 sets of correlations (for men and women separately, correlating work stress with 4 measures of alcohol consumption), only I set of correlations was significantly positive in as many as 4 countries: a significant association among men of greater work stress with greater volume of alcohol consumed, in Costa Rica, India, Nigeria and Sri Lanka. Work stress was significantly associated with multiple measures of increased drinking only among men in Sri Lanka and among women on the Isle of Man. Given these very limited findings, no further analyses of work-stress effects were attempted.

Nineteen of 22 surveys of men obtained responses to the two items combined to measure general psychological distress (self-reported poorer mental health and frequent loneliness). Table 2 shows that, among men, psychological distress was significantly correlated with drinking greater quantities per drinking occasion in 7 countries, and significantly correlated with consuming larger volumes of alcohol per year in ro countries. This is greater consistency than would be expected by chance. In contrast, psychological distress had few relationships with men's frequency of drinking or with men's episodes of exceptionally heavy drinking, and in Uganda psychological distress was associated with lower frequency and volume of men's drinking. Generally, the statistically significant correlations were relatively small; psychological distress, as measured here, can explain only a small part of men's drinking. 
Table 2

Correlations of psychological distress ${ }^{a}$ and drinking ${ }^{b}$

\begin{tabular}{|c|c|c|c|c|c|c|c|c|}
\hline \multirow[b]{2}{*}{ Country } & \multicolumn{2}{|c|}{ Frequency } & \multicolumn{2}{|c|}{ Quantity } & \multicolumn{2}{|c|}{ Volume } & \multicolumn{2}{|c|}{$\begin{array}{c}\text { Heavy episodic } \\
\text { drinking }\end{array}$} \\
\hline & Males & Females & Males & Females & Males & Females & Males & Females \\
\hline Argentina & & & $.231 *$ & $.163 *$ & & & & $.145 \%$ \\
\hline Australia & & $-.096 *$ & & & $.129 * *$ & & & \\
\hline \multicolumn{9}{|l|}{ Belize } \\
\hline Brazil & & & $.265 *$ & & $.294 * *$ & & & \\
\hline Canada & & & $.097 * *$ & $.143 * *$ & $.055 * *$ & $.103 * *$ & $.080 * *$ & $.144 * \%$ \\
\hline Costa Rica & & & & $.208 *$ & $.135 \%$ & & & $.258 * *$ \\
\hline Czech Republic & - & - & - & - & - & - & - & - \\
\hline Great Britain & & & $.145 * *$ & $.101 *$ & $.143 * *$ & $.142^{* * *}$ & - & - \\
\hline India & & - & $.140 * *$ & - & $.150 * *$ & - & & - \\
\hline Isle of Man & & & & & & $.110 *$ & & $.152 * *$ \\
\hline Japan & & & & $.187 * *$ & & $.133 * *$ & & $.170 * *$ \\
\hline \multicolumn{9}{|l|}{ Kazakhstan } \\
\hline New Zealand & & -.148 ** & $.150 * *$ & $.132 * *$ & $.164 * *$ & & & $.129 * *$ \\
\hline Nicaragua & $.211 * *$ & & & & $.155^{*}$ & & & \\
\hline Nigeria & $.139 * *$ & & & & $.108^{*}$ & & & \\
\hline \multicolumn{9}{|l|}{ Peru } \\
\hline Spain & & $.117 *$ & & & & & & \\
\hline Sri Lanka & $.184 *$ & - & $.148 *$ & - & $.172 *$ & - & & - \\
\hline Sweden & - & - & - & - & - & - & - & - \\
\hline Uganda & $-.147 * *$ & & & & $-.110 *$ & & & \\
\hline Uruguay & & & & $.137 *$ & & & & \\
\hline $\begin{array}{l}\text { U.S.A. } \\
\text { (women only) }\end{array}$ & - & - & - & - & - & - & - & - \\
\hline
\end{tabular}

a Loneliness and poor mental health

b More than once a month

$* \mathrm{p}<.05 ; * * \mathrm{p}<.01$

Note: Non-significant relationships are left blank. Long dashes indicate that measurements were not included in those surveys.

Seventeen surveys of women obtained responses to the two items used to measure general psychological distress; however, the surveys included too few women who drank more than monthly in India $(N=20)$ and Sri Lanka $(N=4)$, so the surveys in these countries were used only for analyses of men's drinking. The correlations in Table 2 show that among women, general psychological distress was significantly associated with drinking larger quantities per drinking occasion in 7 countries, drinking larger volumes per year in 4 countries, and being more likely to engage in heavy episodic drinking in 6 countries-all patterns more consistent than would be expected by chance. In contrast, psychological distress was largely unrelated to the frequency of women's drinking, and in Australia and New Zealand drinking frequency was lower among psychologically distressed women. Again, the significant correlations were relatively small in size.

Among men, partnership distress was more consistently related to increased drinking. Table 3 shows correlations that were significantly positive for drinking frequency in 8 countries, for typical drinking quantity in 7 countries, for volume of alcohol consumed in ro countries, and for heavy episodic drinking in 5 countries. Links between men's partnership distress and drinking patterns were most consistent, and often strong, in the Czech Republic, India, Kazakhstan, New Zealand and Spain. As with the correlations with psychological distress, the significant correlations were scattered among many different countries with no obvious geographic or cultural pattern. 
Table 3 shows that significant associations between partnership distress and drinking patterns were less consistent among women than among men, although sometimes more common than would be expected by chance. Women's greater partner distress was associated with more frequent drinking in 4 countries, drinking greater quantities per occasion in 3 countries, drinking larger volumes of alcohol in 8 countries, and engaging In heavy episodic drinking in 4 countries. The strongest associations were between partner distress and women's frequency and volume of drinking, in Kazakhstan and Argentina. However, women with the most partner distress were less likely to engage in heavy episodic drinking in Uganda, and likely to drink less frequently in New Zealand. Again, the significant positive associations of partner distress with alcohol consumption were scattered among countries with no obvious cultural or geographic connections.

Hierarchical linear modeling (HLM) was used to evaluate how, in the populations surveyed, levels of economic development and gender-specific prevalence of alcohol abstinence modified how distress was related to the four measures of drinking. The analyses also took into account how, for each sample, the drinking measures were affected by the gender-specific mean level of the type of distress being analyzed, and by the person's age (associated with drinking behavior in many of the populations surveyed (Wilsnack et al., 2009).

Table 3

Correlations of partnership distress ${ }^{a}$ and drinking ${ }^{b}$

\begin{tabular}{|c|c|c|c|c|c|c|c|c|}
\hline \multirow[b]{2}{*}{ Country } & \multicolumn{2}{|c|}{ Frequency } & \multicolumn{2}{|c|}{ Quantity } & \multicolumn{2}{|c|}{ Volume } & \multicolumn{2}{|c|}{$\begin{array}{l}\text { Heavy episodic } \\
\text { drinking }\end{array}$} \\
\hline & Males & Females & Males & Females & Males & Females & Males & Females \\
\hline Argentina & & $.282 * *$ & & & & $.299 * *$ & & \\
\hline Australia & & & $.116 * *$ & & & & & \\
\hline Belize & $.107 *$ & & & & $.139 * *$ & $.197 *$ & $.124 *$ & $.204 *$ \\
\hline Brazil & & & & & & & & \\
\hline Canada & $.070 * *$ & & & $.113 *$ & $.120 * *$ & $.104 * *$ & $.060 * *$ & $.081^{* *}$ \\
\hline Costa Rica & & & & & $.199 *$ & $.272 *$ & & \\
\hline Czech Republic & $.252 * *$ & $.163 * *$ & $.128 * *$ & & $.340 * *$ & $.164 * *$ & $.159 * *$ & \\
\hline Great Britain & & & $.198 * *$ & $.171 * *$ & $.158 * *$ & $.114 *$ & - & - \\
\hline India & $.208 * *$ & - & $.295 * *$ & - & $.347 * *$ & - & $.219 * *$ & - \\
\hline $\begin{array}{l}\text { Isle of Man } \\
\text { Japan }\end{array}$ & & & & & & $.158 *$ & & $.145 *$ \\
\hline Kazakhstan & $.185 * *$ & $.303 * *$ & $.171 *$ & & $.180 * *$ & $.328 * *$ & & \\
\hline New Zealand & $.156 * *$ & $-.184 * *$ & $.146 * *$ & $.148 * *$ & $.197 * *$ & & & $.116 *$ \\
\hline Nicaragua & & & & & & & - & \\
\hline Nigeria & $.235 * *$ & & & & $.124 *$ & & & \\
\hline Peru & & & & & & & & \\
\hline Spain & $200 * *$ & $.248 * *$ & $.150 *$ & & $.244 * *$ & & & \\
\hline Sri Lanka & & - & & - & & - & & - \\
\hline Sweden & & & & & & & $.152^{* * *}$ & \\
\hline Uganda & & & & & & & & $-.234 *$ \\
\hline Uruguay & & & & & & & & \\
\hline $\begin{array}{l}\text { U.S.A. } \\
\text { (women only) }\end{array}$ & - & & - & & - & & - & \\
\hline
\end{tabular}

a Unhappiness with relationship, inability to talk with partner, quarreling with partner

b More than once a month

$* \mathrm{p}<.05 ; * * \mathrm{p}<.01$

Note: Non-significant relationships are left blank. Long dashes indicate that measurements were not included in those surveys 
We used HLM 6.06 software for these analyses. Each multilevel analysis consisted of two models: the first included only level-one individuallevel predictors (age and the specific type of distress), and the second added level-two societal-level predictors (per capita GDP, and the gender-specific abstinence rates and mean distress levels in the populations surveyed). The second model also in- cluded terms for possible interaction effects of individual stress levels with GDP and abstinence rate. The numerical results for the analyses of the second model are given in Tables 4 and 5. We used group mean centering for the level-one variables and grand mean centering for the level-two variables, so the numbers in the tables should not be interpreted simply as effect sizes.

\section{Table 4}

Hierarchical linear models of psychological distress and drinking frequency, quantity, volume and heavy episodic drinking

\begin{tabular}{|c|c|c|c|c|c|c|c|c|}
\hline \multirow{2}{*}{$\begin{array}{l}\text { Level } 2 \\
\text { analysis }\end{array}$} & \multicolumn{2}{|c|}{ Frequency } & \multicolumn{2}{|c|}{ Quantity } & \multicolumn{2}{|c|}{ Volume } & \multicolumn{2}{|c|}{$\begin{array}{c}\text { Heavy episodic } \\
\text { drinking }\end{array}$} \\
\hline & Males & Females & Males & Females & Males & Females & Males & Females \\
\hline \multicolumn{9}{|l|}{ Fixed effects } \\
\hline Intercept & 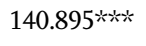 & 152.131 秋次 & 72.950 **⿲二 & 36.318 栨次 & 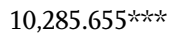 & $6,890.732^{*} \cdots * *$ & & \\
\hline $\begin{array}{l}\text { GDP-PPP } \\
\text { (log) }\end{array}$ & & & & & & $-1,323.594 *$ & & \\
\hline \multicolumn{9}{|l|}{$\begin{array}{l}\text { Abstinence } \\
\text { rate }\end{array}$} \\
\hline $\begin{array}{l}\text { Mean } \\
\text { psycho- } \\
\text { logical } \\
\text { distress }\end{array}$ & & $-51.106 * *$ & & & & $-2,683.628 * * *$ & & \\
\hline $\begin{array}{l}\text { Age slope } \\
\text { intercept }\end{array}$ & 1.617 敞火 & $1.402^{2}$ & $-.556^{* \cdots *}$ & -.478 *⿻一火火 & & $20.175 *$ & -.035 *⿰冫欠火火 & $-.555 * \cdots$ \\
\hline $\begin{array}{l}\text { Psychologi- } \\
\text { cal distress } \\
\text { slope inter- } \\
\text { cept }\end{array}$ & & & $1.911^{*}{ }^{2}$ & & $452.963 *$ & & $.060 *$ & $.129 *$ \\
\hline $\begin{array}{l}\text { Psychologi- } \\
\text { cal distress } \\
\text { x GDP-PPP }\end{array}$ & & & & & & & & \\
\hline $\begin{array}{l}\text { Psychologi- } \\
\text { cal distress } \\
\text { x abstinence } \\
\text { rate }\end{array}$ & $19.462 * *$ & & & & $2,992.587 *$ & & & \\
\hline
\end{tabular}


Table 5

Hierarchical linear models of partnership distress and drinking frequency, quantity, volume and heavy episodic drinking

\begin{tabular}{|c|c|c|c|c|c|c|c|c|}
\hline \multirow{2}{*}{$\begin{array}{l}\text { Level } 2 \\
\text { analysis }\end{array}$} & \multicolumn{2}{|c|}{ Frequency } & \multicolumn{2}{|c|}{ Quantity } & \multicolumn{2}{|c|}{ Volume } & \multicolumn{2}{|c|}{$\begin{array}{c}\text { Heavy episodic } \\
\text { drinking }\end{array}$} \\
\hline & Males & Females & Males & Females & Males & Females & Males & Females \\
\hline \multicolumn{9}{|l|}{ Fixed effects } \\
\hline Intercept & $130.229 * \cdots *$ & $99.842 * * *$ & $66.575 * * *$ & $43.113 * * *$ & $8,732.165$ *** & $4,351.878^{2}$ & $1.046 * *$ & \\
\hline \multicolumn{9}{|l|}{$\begin{array}{l}\text { GDP-PPP } \\
\text { (log) }\end{array}$} \\
\hline \multicolumn{9}{|l|}{$\begin{array}{l}\text { Abstinence } \\
\text { rate }\end{array}$} \\
\hline \multicolumn{9}{|l|}{$\begin{array}{l}\text { Mean } \\
\text { partnership } \\
\text { distress }\end{array}$} \\
\hline $\begin{array}{l}\text { Age slope } \\
\text { intercept }\end{array}$ & $1.432 * * *$ & $1.521 * * *$ & $-.390 * x^{\prime} *$ & $-.344 * * * *$ & $20.582 *$ & & $-.033^{* \ldots * k}$ & 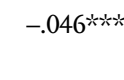 \\
\hline $\begin{array}{l}\text { Partnership } \\
\text { distress } \\
\text { slope } \\
\text { intercept }\end{array}$ & $5.980 * * *$ & & $1.912^{2}$ & & 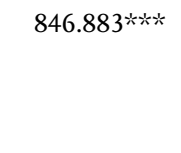 & $339.219 * * * *$ & $.091 * * *$ & .075 栨次 \\
\hline \multicolumn{9}{|l|}{$\begin{array}{l}\text { Partnership } \\
\text { distress } \\
\text { x GDP-PPP }\end{array}$} \\
\hline $\begin{array}{l}\text { Partnership } \\
\text { distress } \\
\text { xabstinence } \\
\text { rate }\end{array}$ & & & & & & & & \\
\hline
\end{tabular}

Three results were nearly consistent in all the models, for both men and women. First, among the populations surveyed, the frequency and volume of alcohol consumption tended to increase with age, but the quantity of alcohol consumed on drinking occasions and the likelihood of any heavy episodic drinking declined somewhat in older individuals. Second, the predictions that economic development and the prevalence of abstinence would modify the connections between distress and drinking were not supported, with one exception. Contrary to our prediction, psychologically distressed men drank more frequently only where male drinking was relatively uncommon; that is, where there were relatively high rates of male abstinence from alcohol. Finally, there were no significant main effects on drinking patterns from gender-specific abstinence rates or from economic development; social influences on drinking are not that simple.

The prediction that people who were more psychologically distressed would drink more was generally confirmed for men, as shown in Table 4 . Men with higher scores on psychological distress drank greater volumes of alcohol, drank more per drinking occasion, and were more likely to engage in heavy episodic drinking. The results were not the 
same for women. The only drinking pattern that increased significantly with women's individual level of psychological distress was heavy episodic drinking. However, in places where there were lower mean levels of women's psychological distress, women tended to drink more frequently and to consume larger volumes of alcohol.

Men also drank more if they had distressed relationships (marital or cohabiting). As shown in Table 5, those reporting higher levels of partner distress drank more frequently, drank larger amounts per occasion, consumed larger quantities of alcohol, and were more likely to engage in heavy episodic drinking. On the other hand, women with greater partner distress consumed larger volumes of alcohol and were significantly more likely at some time to engage in heavy episodic drinking, but in general did not drink significantly more frequently and did not typically consume larger amounts of alcohol per drinking occasion.

\section{Discussion}

How is it possible to make sense of these complex and apparently divergent findings? In particular, how can we reconcile the scattered positive correlations of distress with drinking in separate countries, and the apparently systematic connections of distress to drinking in hierarchical linear models, at least among men? The most likely answer is this: distress is associated with increased drinking, but the direct connections are weak. In separate surveys from individual countries, these connections may sometimes be too weak to be detected or may be hidden by other influences on drinking behavior. As a result, connections between distress and drinking appear in some countries but not in others, with no simple pattern to identify which countries will have the strongest connections. However, when all the surveys are combined into one very large sample, the connections can be detected more reliably than in the smaller individual surveys; we also found weak but significant associations between distress and drinking if we simply correlated distress and drinking variables in the total sample (not shown here).

Several other patterns in the data may be meaningful. First, the multivariate models show that among both men and women who drank, drinking frequency and volume tended to increase among older individuals, consistent with earlier
GENACIS analyses of countries outside of Europe and North America (Wilsnack et al., 2009). (On the other hand, exceptionally heavy drinking on drinking occasions became less common with increasing age; older individuals may drink more often but perhaps not as much at any one time.) Second, distress and drinking were to some degree more consistently connected among men than among women, consistent with conventional wisdom that men are more likely than women to choose alcohol as a method of coping with distress (Holahan et al., 200I). Third, among men the drinking pattern most clearly related to levels of distress was consumption of greater volumes of alcohol, possibly because this measure showed effects of all the other drinking patterns: frequency, quantity per occasion and heavy episodic drinking. Fourth, psychological distress was largely unrelated to frequency of drinking, consistent with findings about effects of stressful life events reported in the United States (Dawson et al., 2005). The exception was that in societies where larger percentages of men did not drink at all, men who did drink frequently and thus atypically tended to be men who were more distressed. Finally, it is clear that drinking patterns are not determined simply by levels of abstinence or of prosperity in given countries; to understand influences at the level of whole societies, subtler or more complex measures of cultural and social structural differences are needed.

The connections here between distress and drinking may look small and scattered in part because of limitations of our measurements. The GENACIS surveys contained only a few questions that indicated distress, and no specific questions about how people expected or used alcohol to help them deal with distress. There was also no way to estimate how chronic or severe the stressors were. Finally, the drinking patterns measured were based largely on alcohol consumption that was not causing problems. However, those limitations should have created a bias against finding significant links between distress and drinking; the fact that such links did occur is therefore more meaningful, not less so.

The challenge is to determine what implications and lessons we can draw from these findings, for policies to prevent or counteract problem drinking. An obvious implication is that simply trying to reduce levels of distress among people who drink alcohol appears unlikely to be an effective intervention by itself, because the connections between dis- 
tress and drinking appear too weak. What may be more useful and important is to better understand what happens in the process between experiencing distress and drinking in response. From past research it appears that drinking problems are more likely to increase when people expect that alcohol is a good way to reduce their feelings of distress, and when people begin to drink deliberately to drown their sorrows. It is also possible that if drinking to cope with distress becomes a habit, the effects of alcohol itself, behaviorally and neurologically, may cause distress that helps to perpetuate drinking in a vicious circle. However, to learn whether these processes are consistent or vary, for men and women and cross-culturally, will require further multinational research with (a) better measures of subjective distress, (b) good measures of stressreducing expectancies and drinking as a conscious coping strategy, and (c) better information about how cultural contexts influence how people perceive and express distress, and how they perceive the effects of alcohol. It is hoped that the modest start in the research presented here will stimulate such further and better analyses.

\section{Acknowledgments}

Preparation of this paper was supported by Grant Number RoIAAoI5775 from the U.S. National Institute on Alcohol Abuse and Alcoholism (NIAAA)/National Institutes of Health (NIH). The content is solely the responsibility of the authors and does not necessarily represent the official views of the NIAAA or the NIH.

The data used in this paper are from the project Gender, Alcohol and Culture: An International Study (GENACIS). GENACIS is a collaborative international project affiliated with the Kettil Bruun Society for Social and Epidemiological Research on Alcohol and is co-ordinated by GENACIS partners from the University of North Dakota (U.S.A.), Aarhus University (Denmark), the Alcohol Research Group/Public Health Institute (U.S.A.), the Centre for Addiction and Mental Health (Canada), the AER Centre for Alcohol Policy Research / Turning Point Alcohol and Drug Centre (Australia) and the Addiction Info Switzerland Research Institute (Switzerland). Support for aspects of the project has come from the World Health Organization, the Quality of Life and Management of Living Resources Programme of the European Commission (Concerted
Action QLG4-CT-200I-oI96), the NIAAA/NIH (Grants R2I AAoI294I and RoI AAoI5775), the German Federal Ministry of Health, the Pan American Health Organization and Swiss national funds. Support for individual country surveys was provided by government agencies and other national sources. The study leaders and funding sources for data sets used in this paper are:

Argentina: Myriam Munné, M.S., World Health Organization; Australia: Paul Dietz, Ph.D., National Health and Medical Research Council (Grant 398500); Belize: Claudina Cayetano, M.D., Pan American Health Organization; Brazil: Florence Kerr-Corréa, M.D., Ph.D., Foundation for the Support of São Paulo State Research (Fundação de Amparo a Pesquisa do Estado de São Paulo, FAPESP) (Grant oI/03I50-6); Canada: Kathryn Graham, Ph.D., Canadian Institutes of Health Research (CIHR); Costa Rica: Julio Bejarano, M.Sc., World Health Organization; Czech Republic: Ladislav Csémy, Ph.D., Ministry of Health (Grant MZ 23752); Great Britain: Martin Plant, Ph.D., and Moira Plant, Ph.D., Alcohol Education and Research Council; European Forum for Responsible Drinking; University of the West of England, Bristol; India: Vivek Benegal, M.D., World Health Organization; Isle of Man: Martin Plant, Ph.D., and Moira Plant, Ph.D., Isle of Man Medical Research; University of the West of England, Bristol; Japan: Shinji Shimizu, Ph.D., Japan Society for the Promotion of Science (Grant I34I0072); Kazakhstan: Bedel Sarbayev, Ph.D., World Health Organization; New Zealand: Jennie Connor, Ph.D., Otago University Research Grant; Nicaragua: José Trinidad Caldera Aburto, M.D., Ph.D., Pan American Health Organization; Nigeria: Akanidomo Ibanga, M.Sc., World Health Organization; Peru: Marina Piazza, MPH, Sc.D., Pan American Health Organization; Spain: Juan Carlos Valderrama, M.D., Dirección General de Atención a la Dependencia, Conselleria de Sanidad, Generalitat Valenciana; Comisionado do Plan de Galicia sobre Drogas, Conselleria de Sanidade, Xunta de Galicia; Dirección General de Drogodependencias y Servicios Sociales, Gobierno de Cantabria; Sri Lanka: Siri Hettige, Ph.D., World Health Organization; Sweden: Karin Helmersson Bergmark, Ph.D., Ministry for Social Affairs and Health, Sweden; Uganda: M. Nazarius Tumwesigye, Ph.D., World Health Organization; U.S.A.: Sharon C. Wilsnack, Ph.D., National Institute on Alcohol Abuse and Alcoholism/National Institutes of Health 
(Grant RoI AAoo46ro); Uruguay: Raquel Magri, M.D., World Health Organization.

\section{References}

Ahola, K., Honkonen, T., Pirkola, S., Isometsä, E., Kalimo, R., Nykyri, E., . . Lönnqvist, J. (2006). Alcohol dependence in relation to burnout among the Finnish working population. Addiction, 101, I438-I443.

Armeli, S., Carney, M. A., Tennen, H., Affleck, G., \& O’Neil, T. (2000) Stress and alcohol use: A daily process examination of the stressorvulnerability model. Journal of Personality and Social Psychology, 78, 979-994.

Armeli, S., Todd, M., \& Mohr, C. (2005). A daily process approach to individual difference in stress-related alcohol use. Journal of Personality, 73, I657-1686.

Aseltine, R. J. J., \& Gore, S. L. (2000). The variable effects of stress on alcohol use from adolescence to early adulthood. Substance Use Q Misuse, 35, 643-668.

Blomeyer, D., Treutlein, J., Esser, G., Schmidt, M. H., Schumann, G., \& Laucht, M. (2008). Interaction between CRHRi gene and stressful life events predicts adolescent heavy alcohol use. Biological Psychiatry, 63, I46-I5I.

Blume, A. W., Resor, M. R., Villanueva, M. R., \& Braddy, L. D. (2009). Alcohol use and comorbid anxiety, traumatic stress, and hopelessness among Hispanics. Addictive Behaviors, 34, 7097I3.

Bobak, M., Pikhart, H., Kubinova, R., Malyutina, S., Pajak, A., Sebakova, H., ... Marmot, M. (2005). The association between psychosocial characteristics at work and problem drinking: A cross-sectional study of men in three Eastern European urban populations. Occupational and Environmental Medicine, 62, 546-550.

Booth, C., \& Hasking, P. (2009). Social anxiety and alcohol consumption: The role of alcohol expectancies and reward sensitivity. Addictive Behaviors, 34, 730-776.

Boscarino, J. A., Adams, R. E., \& Galea, S. (2006). Alcohol use in New York after the terrorist attacks: A study of the effects of psychological trauma on drinking behavior. Addictive Behaviors, 31, 606-62I.

Bray, R. M., Fairbank, J. A., \& Marsden, M. E.
(I999). Stress and substance use among military men and women. American Journal of Drug and Alcohol Abuse, 25, 239-256.

Breese, G. R., Chu, K., Dayas, C. V., Funk, D., Knapp, D. J., Koob, G. F., . . Weiss, F. (2005). Stress enhancement of craving during sobriety: A risk for relapse. Alcoholism: Clinical and Experimental Research, 29, 185-195.

Brennan, P. L., Schutte, K. K., \& Moos, R. H. (I999). Reciprocal relations between stressors and drinking behavior: A three-wave panel study of late middle-aged and older women and men. Addiction, 94, 737-758.

Breslau, N., Davis, G. C., \& Schultz, L. R. (2003). Posttraumatic stress disorder and the incidence of nicotine, alcohol, and other drug disorders in persons who have experienced trauma. Archives of General Psychiatry, 60, 289-294.

Buchmann, A. F., Schmid, B., Blomeyer, D., Zimmermann, U. S., Jennen-Steinmetz, C, Schmidt, M. H., ... Laucht, M. (20I0). Drinking against unpleasant emotions: Possible outcome of early onset of alcohol use? Alcoholism: Clinical and Experimental Research, 34, I052-I057.

Buckner, J. D., \& Turner, R. J. (2009). Social anxiety disorder as a risk factor for alcohol use disorders: A prospective examination of parental and peer influences. Drug and Alcohol Dependence, 100, I28-I37.

Burazeri, G., \& Kark, J. D. (2010). Prevalence and determinants of binge drinking in middle age in a transitional post-communist country: A population-based study in Tirana, Albania. Alcohol and Alcoholism, 45, I80-I87.

Carrigan, M. H., \& Randall, C. L. (2003). Selfmedication in social phobia: A review of the alcohol literature. Addictive Behaviors, 28, 269284.

Cooper, M. L., Russell, M., Skinner, J. B., Frone, M. R., \& Mudar, P. (1992). Stress and alcohol use: Moderating effects of gender, coping, and alcohol expectancies. Journal of Abnormal Psychology, 101, I39-I52.

Costanzo, P. R., Malone, P. S., Belsky, D., Kertesz, S., Pletcher, M., \& Sloan, F. A. (2007). Longitudinal differences in alcohol use in early adulthood. Journal of Studies on Alcohol and Drugs, 68, 727-737.

Dawson, D. A., Grant, B. G., \& Li, T. K. (2007). Impact of age at first drink on stress-reactive drinking. Alcoholism: Clinical and Experimental Research, 31, 69-77. 
Dawson, D. A., Grant, B. G., \& Ruan, W. J. (2005). The association between stress and drinking: Modifying effects of gender and vulnerability. Alcohol and Alcoholism, 40, 453-46o.

Dorfman, D. H., Trokel, M., Lincoln, A. K., \& Mehta, S. D. (20I0). Increased prevalence of behavioral risks among adolescent and young adult women with psychological distress in the emergency department. Pediatric Emergency Care, 26, 93-98.

Droomers, M., Schrijvers, C. T. M., Stronks, K., Van De Mheen, D., \& Mackenbach, J. P. (I999). Educational differences in excessive alcohol consumption: The role of psychosocial and material stressors. Preventive Medicine, 29, I-IO.

Eggleson, A., Woolaway-Bickel, K., \& Schmidt, N. B. (2004). Social anxiety and alcohol use: Evaluation of the moderating and mediating effects of alcohol expectancies. Journal of Anxiety Disorders, 18, 33-49.

Enoch, M. A. (20II). The role of early life stress as a predictor for alcohol and drug dependence. Psychopharmacology, 214, I7-3I.

Fritch, A. M., Mishkind, M., Reger, M. A., \& Gahm, G. A. (20IO). The impact of childhood abuse and combat-related trauma on postdeployment adjustment. Journal of Traumatic Stress, 23, 248-254.

Gaher, R. M., Simons, J. S., Jacobs, G. A., Meyer, D., \& Johnson-Jiminez, E. (2006). Coping motives and trait negative affect: Testing mediation and moderation models of alcohol problems among American Red Cross disaster workers who responded to the September II, 200I terrorist attacks. Addictive Behaviors, 31, I3I9-I330.

Gradus, J. L., Street, A. E., Kelly, K., \& Stafford, J. (2008). Sexual harassment experiences and harmful alcohol use in a military sample: Differences in gender and the mediating role of depression. Journal of Studies on Alcohol and Drugs, 69, 348-351.

Graham, K., \& Schmidt, G. (I999). Alcohol use and psychosocial well-being among older adults. Journal of Studies on Alcohol, 60, 345-35I.

Grieger, T. A., Fullerton, C. S., Ursano, R. J., \& Reeves, J. J. (2003). Acute stress disorder, alcohol use, and perception of safety among hospital staff after the sniper attacks. Psychiatric Services, 54, I383-1387.

Grotmol, K. S., Vaglum, P., Ekeberg, O., Gude, T.,
Aasland, O. G., \& Tyssen, R. (2010). Alcohol expectancy and hazardous drinking: A 6-year longitudinal and nationwide study of medical doctors. European Addiction Research, 16, I7-22.

Grzywacz, J. G., \& Almeida, D. M. (2008). Stress and binge drinking: A daily process examination of stressor pile-up and socioeconomic status in affect regulation. International Journal of Stress Management, 15, 364-80.

Hagihara, A., Tarumi, L., \& Nobutomo, K. (2003). Positive and negative effects of social support on the relationship between work stress and alcohol consumption. Journal of Studies on Alcohol, 64, 874-883.

Ham, L. S. (2009). Positive social alcohol outcome expectancies, social anxiety, and hazardous drinking in college students. Cognitive Therapy and Research, 33, 615-623.

Ham, L. S., \& Hope, D. A. (2006). Incorporating social anxiety into a model of college problem drinking: Replication and extension. Psychology of Addictive Behaviors, 20, 348-355.

Hasin, D. S., Keyes, K. M., Hatzenbuehler, M. L., Aharonovich, E. A., \& Alderson, D. (2007). Alcohol consumption and posttraumatic stress after exposure to terrorism: Effects of proximity, loss, and psychiatric history. American Journal of Public Health, 97, 2268-2275.

Hasking, P. A., \& Oei, T. P. S. (2008). Incorporating coping into an expectancy framework for explaining drinking behavior. Current Drug Abuse Reviews, 1, 20-35.

Helzer, J. E., Badger, G. J., Searles, J. S., Rose, G. L., \& Mongeon, J. A. (2006). Stress and alcohol consumption in heavily drinking men: Two years of daily data using interactive voice response. Alcoholism: Clinical and Experimental Research, 30, 802-8II.

Hodgins, D. C., Williams, R., \& Munro, G. (2009). Workplace resonsibility, stress, alcohol availability and norms as predictors of alcohol consumption-related problems among employed workers. Substance Use Q Misuse, 44, 20622069.

Holahan, C. J., Moos, R. H., Holahan, C. K., Cronkite, R. C., \& Randall, P. K. (200I). Drinking to cope, emotional distress and alcohol use and abuse: A ten-year model. Journal of Studies on Alcohol, 62, I90-198.

Jacobson, I. G., Ryan, M. A. K., Hooper, T. I., Smith, T. C., Amoroso, P. J., Boyko, E. J., . . . Bell, N. S. (2008). Alcohol use and alcohol- 
related problems before and after military combat deployment. Journal of the American Medical Association, 300, 663-675.

Kaysen, D., Dillworth, T. M., Simpson, T., Waldrop, A., Larimer, M. E., \& Resick, P. A. (2007). Domestic violence and alcohol use: Trauma-related symptoms and motives for drinking. Addictive Behaviors, 32, I272-1283.

Koob, G., \& Kreek, M. J. (2007). Stress, dysregulation of drug reward pathways, and the transition to drug dependence. American Journal of Psychiatry, 164, II49-II59.

Kouvonen, A., Kivimäki, M., Cox, S. J., Poikolainen, K., Cox, T., \& Vahtera, J. (2005). Job strain, effort-reward imbalance, and heavy drinking: A study in 40,85I employees. Journal of Occupational and Environmental Medicine, 47, 5OI-5I3.

Krause, J. S., \& Crewe, N. M. (I990). Long-term prediction of self-reported problems following spinal cord injury. Paraplegia, 28, I86-202.

Kushner, M. G., Abrams, K., \& Borchardt, C. (2000). The relationship between anxiety disorders and alcohol use disorders: A review of major perspectives and findings. Clinical Psychology Review, 20, I49-I7I.

Lawton, J., \& Simpson, J. (2009). Predictors of alcohol use among people experiencing chronic pain. Psychology, Health and Medicine, 14, 487-50I.

Liu, S., Wang, M., Zhan, Y., \& Shi, J. (2009). Daily work stress and alcohol use: Testing the crosslevel moderation effects of neuroticism and job involvement. Personnel Psychology, 62, 575-597.

Lloyd, D. A., \& Turner, R. J. (2008). Cumulative lifetime adversities and alcohol dependence in adolescence and young adulthood. Drug and Alcohol Dependence, 93, 2I7-226.

McDevitt-Murphy, M. E., Williams, J. L., Bracken, K. L., Fields, J. A., Monahan, C. J., \& Murphy, J. G. (20I0). PTSD symptoms, hazardous drinking, and health functioning among U.S. OEF and OIF veterans presenting to primary care. Journal of Traumatic Stress, 23, I08-III.

Moos, R. H., Brennan, P. L., Schutte, K. K., \& Moos, B. S. (20IO). Older adults' health and late-life drinking patterns: A 20 -year perspective. Aging \& Mental Health, 14, 33-43.

Morris, E. P., Stewart, S. H., \& Ham, L. S. (2005). The relationship between social anxiety disorder and alcohol use disorders: A critical review. Clinical Psychology Review, 25, 734-760.

Najdowski, C. J., \& Ullman, S. E. (2009). Prospec- tive effects of sexual victimization on PTSD and problem drinking. Addictive Behaviors, 34, 965-968.

Ng, D. M., \& Jeffery, R. W. (2003). Relationships between perceived stress and health behaviors in a sample of working adults. Health Psychology, 22, 638-642.

Niemi, R. G., Carmines, E. G., \& McIver, J. P. (I986). The impact of scale length on reliability and validity. Quality a Quantity, 20, 37I-376.

Olff, M., Langeland, W., Draijer, N., \& Gersons, B. P. R. (2007). Gender differences in posttraumatic stress disorder. Psychological Bulletin, 133, I83-204.

Park, C. L., Armeli, S., \& Tennen, H. (2004). The daily stress and coping process and alcohol use among college students. Journal of Studies on Alcohol, 65, I26-I35.

Perreira, K. M., \& Sloan, F. A. (200I). Life events and alcohol consumption among mature adults: A longitudinal analysis. Journal of Studies on Alcohol, 62, 50I-508.

Pohorecky, L. A. (I99I). Stress and alcohol interaction: An update of human research. Alcoholism: Clinical and Experimental Research, 15, 438-459.

Richman, J. A., Rospenda, K. M., Flaherty, J. A., \& Freels, S. (200I). Workplace harassment, active coping, and alcohol-related outcomes. Journal of Substance Abuse, 13, 347-366.

Richman, J. A., Shinsako, S. A., Rospenda, K. M., Flaherty, J. A., \& Freels, S. (2002). Workplace harassment/abuse and alcohol-related outcomes: The mediating role of psychological distress. Journal of Studies on Alcohol, 63, 4I2-4I9.

Riley, J. L., \& King, C. (2009). Self-report of alcohol use for pain in a multi-ethnic community sample. Journal of Pain, 10, 944-952.

Ritter, J. D., McCauley, J. L., Amstadter, A. B., Richardson, L., Kilpatrick, D., Tran, T. L., . . . Acierno, R. (20II). Mental health correlates of post disaster increases in alcohol and cigarette smoking: A Vietnamese study. International Journal of Mental Health and Addiction, 9, II8I25.

Robertson, A. A., \& Xu, X., \& Stripling A. (20IO). Adverse events and substance use among female adolescent offenders: Effects of coping and family support. Substance Use Q Misuse, 45, 45I-472.

Šakušić, A., Zoričić, Z., Avdibegović, E., Pavlović, 
S., Gašpar, V., Ilić, S., . . Torre, R. (2009). Intensity of posttraumatic stress disorder symptoms in relation to alcohol use in war veterans: Experiences from BosniaHerzegovina. Alcoholism, 45, 95-105.

Sarin, S., \& Nolen-Hoeksema, S. (2010). The dangers of dwelling: An examination of the relationship between rumination and consumptive coping in survivors of childhood sexual abuse. Cognition and Emotion, 24, 7I-85.

Schneier, F. R., Foose, T. E., Hasin, D. S., Heimberg, R. G., Liu, S-M., Grant, B. F., ... Blanco, C. (20I0). Social anxiety disorder and alcohol use disorder co-morbidity in the national epidemiologic survey on alcohol and related conditions. Psychological Medicine, 40, 977-988.

Skaff, M. M., Finney, J. W., \& Moos, R. H. (I999). Gender differences in problem drinking and depression: Different vulnerabilities? American Journal of Community Psychology, 26, 25-54.

Taylor, B., Wilsnack, S. C., \& Rehm, J. (2008). Gender, alcohol, and culture: An international study (GENACIS). In K. Graham, S. Bernards, M. Munné, \& S. C. Wilsnack (Eds.), Unhappy hours: Alcohol and partner aggression in the Americas (p. I6). Washington, D.C., U.S.A.: Pan American Health Organization.

Testa, M., Livingston, J. A., \& Hoffman, J. H. (2007). Does sexual victimization predict subsequent alcohol consumption? A prospective study among a community sample of women. Addictive Behaviors, 32, 2926-2939.

Tran, G., Haaga, D., \& Chambless, D. (I997). Expecting that alcohol use will reduce social anxiety moderates the relation between social anxiety and alcohol consumption. Cognitive Therapy and Research, 21, 535-553.

Uhart, M., \& Wand, G. S. (2008). Stress, alcohol and drug interaction: An update of human research. Addiction Biology, 14, 43-64.

Ullman, S. E., Filipas, H. H., Townsend, S. M., \& Starzynski, L. L. (2005). Trauma exposure, posttraumatic stress disorder and problem drinking in sexual assault survivors. Journal of Studies on Alcohol, 66, 6ro-6rg.

van Praag, L., Bracke, P., Christiaens, W., Levecque, K., \& Pattyn, E. (2009). Mental health in a gendered context: Gendered community effect on depression and problem drinking. Health Q Place, 15, 990-998.

Vaughn, M. G., Fu, Q., Delisi, M., Beaver, K. M.,
Perron, B. E., \& Howard, M. O. (2010). Criminal victimization and comorbid substance use and psychiatric disorders in the United States: Results from the NESARC. Annals of Epidemiology, 20(4), 28I-288.

Welte, J. W., \& Mirand, A. L. (I995). Drinking, problem drinking, and life stressors in the elder general population. Journal of Studies on Alcohol, 56, 67-73.

Wilk, J. E., Bliese, P. D., Kim, P. Y., Thomas, J. L., McGurk, D., \& Hoge, C. W. (2010). Relationship of combat experiences to alcohol misuse among U.S. soldiers returning from the Iraq war. Drug and Alcohol Dependence, 108, II5-I2I.

Wilsnack, R. W., Wilsnack, S. C., Kristjanson, A. F., Vogeltanz-Holm, N. D., \& Gmel, G. (2009). Gender and alcohol consumption: Patterns from the multinational GENACIS project. Addiction, 104, I487-I500.

Wilsnack, S. C., Wilsnack, R. W., Kristjanson, A. F., Vogeltanz-Holm, N. D., \& Harris, T. R. (2004). Childhood sexual abuse and alcohol use among women: Setting the stage for risky sexual behavior. In L. J. Koenig, L. S. Doll, A. O'Leary, \& W. Pequegnat (Eds.), From child sexual abuse to adult sexual risk: Trauma, revictimization, and intervention (pp. I8I-200). Washington, D.C., U.S.A.: American Psychological Association.

Witkiewitz, K., \& Villarroel, N. A. (2009). Dynamic association between negative affect and alcohol lapses following alcohol treatment. Journal of Consulting and Clinical Psychology, 77, 633-644.

Wu, P., Bird, H. R., Liu, X., Duarte, C. S., Fuller, C., Fan, B., ... Canino, G. J. (20I0). Trauma, posttraumatic stress symptoms, and alcoholuse initiation in children. Journal of Studies on Alcohol, 71, 326-334.

Yokoyama, M., Yokoyama, T., Funazu, K., Yamashita, T., Kondo, S., Hosoai, H., . . Nakamura H. (2009). Associations between headache and stress, alcohol drinking, exercise, sleep, and comorbid health conditions in a Japanese population. Journal of Headache and Pain, 10, I77-I85.

Zimmermann, P., Wittchen, H. U., Höfler, M., Pfister, H., Kessler, R. C., \& Lieb, R. (2003). Primary anxiety disorders and the development 
of subsequent alcohol use disorders: A 4-year community study of adolescents and young adults. Psychological Medicine, 33, I2II-I222. 